\title{
Multiple Traits-based Analysis of Tartary Buckwheat Landraces Using GGE-Biplot
}

\author{
Bal K. Joshi \\ Genebank, Nepal Agricultural Research Council \\ Khumaltar, Lalitpur \\ e-mail: joshibalak@yahoo.com
}

\begin{abstract}
Selection of landraces using multiple traits can be considered more effective in crop breeding program. The objective was to enhance the yield performance of landraces of Tartary buckwheat through pure line selection method. Seven landraces were selected from the evaluation trials of 105 accessions in 2007 and 2008 based on the grain yield per plant and analyzed by genotype by trait (GT) biplot using seven quantitative traits: plant height, grain yield, number of leaves, number of grains, days to maturity, 500-grain weight and number of primary branches. The landrace, Ghyuri was found to be the best landrace based on the multiple traits analysis and it produced the highest grain yield (5.36 g per plant) and had the highest number of grains (276). The weight of 500-grain was the lowest (8.08 g) in check variety, i.e., Kabre Tite. Ghyuri followed by MY-2-33-1 had higher values for all these traits, where as Kabre Tite had below average values for all traits.
\end{abstract}

Key words: Fagopyrum tataricum, genotype by trait biplot, landrace enhancement, selection

\section{Introduction}

Buckwheat (Fagopyrum spp.) is the staple and life supporting crop in the remote food deficit areas (northern part) of Nepal. Among the two cultivated buckwheat species i.e., common buckwheat (F. esculentum ssp. esculentum Moench, $2 \mathrm{n}=2 \mathrm{x}=16)$ and Tartary buckwheat ( $F$. tataricum ssp. tataricum Gaertn., $2 \mathrm{x}=2 \mathrm{n}=16$ ), common buckwheat is widely cultivated. However, priority is now given on Tartary buckwheat mainly because of its high and stable yield due to its self-compatibility, low seed abortion, and tolerance to stresses such as frost (Baniya et al. 1995 \& Campbell 1995). Additionally it has higher nutritional and medicinal values, especially in respect to a high antioxidant activity in terms of its flavonoid content. As an example, its seed rutin content is approximately 100 times (0.8-1.7\%) higher than that found in common buckwheat (0.01\%) (Fabjan et al. 2003).

In mountain areas of Nepal, farmers are maintaining different landraces of Tartary buckwheat (also called mountain buckwheat), some of which are very unique e.g., Bhate Phaper (rice Tartary buckwheat) which has a non-adhering hull. Variation in Nepalese buckwheat genetic resources was reported by a number of scientists at phenotypic and genotypic levels (Baniya et al. 1995, Sherchand \& Ujihara 1995, Baniya et al. 2001 \& Bimb et al. 2001). However, farmers have to depend on their traditional landraces due to lack of high yielding varieties. Different breeding strategies can be used to develop high yielding varieties of buckwheat e.g., mass selection in common buckwheat and pure line selection in Tartary buckwheat (Campbell 2003). Pedigree selection and line selection are also the common methods of breeding (Honda 1992 \& Inoue et al. 2002) after hybridization. In any types of breeding methods, selection is the major part and plays significant role. To enhance the selection process more effectively, GGE biplot (Yan et al. 2000) can be used. GGE biplot, a graphical displaying computer software developed by Yan et al. (2000) allows visual examination of the genotypic performance with regards to traits (Yan et al. 2000). GGE biplot has also been effectively used for varieties evaluation tested in multienvironments considering multiple traits in different crop species (Yan et al. 2000) for example, wheat (Yan et al. 2000), soybean (Yan \& Rajcan 2002), barley (Dehghani et al. 2006), oat (Yan \& Frégeau-Reid 2008). 
A genotype by trait biplot (GT Biplot), a part of the GGE biplot technique, is a useful tool for exploring multiple traits data and for selecting genotypes based on multiple traits, because it graphically displays the trait associations across and the trait profiles of the genotypes (Yan \& Rajcan 2002). GGE biplot is generally constructed by the first two principal components ( $\mathrm{PC}_{1}$ $\& \mathrm{PC}_{2}$ ) derived from singular value decomposition (Yan et al. 2000) to represent the original matrix. The process of decomposing matrix into its component matrices, is called singular value decomposition, the result of which is principal components. Both $\mathrm{PC}_{1}$ and $\mathrm{PC}_{2}$ should explain a large proportion of the total variation to approximately display the genotype by trait in a biplot (Yan 2001).

GT biplot tool was used here to select the landraces of Tartary buckwheat considering multiple traits. The landraces collected from East Nepal were evaluated and analyzed by GT biplot analysis with the objective of developing better landraces suitable to East Nepal.

\section{Methodology}

\section{Plant materials}

There were a total of 155 and 192 accessions of Tartary buckwheat including three controls (i.e., Dolpa Tite, Kabre Tite and Khumal Tite) in 2007 and 2008 trials respectively. Some of these accessions were selected from Genetic Seed House of Nepal Agricultural Research Council (NARC), Kathmandu and some were collected from western Nepal. Among these accessions, 87 accessions were collected from western Nepal and 105 from eastern Nepal. The GGE biplot analysis of western collections is reported elsewhere (Joshi \& Okuno 2010) and analysis of eastern collections is reported in this paper.

\section{Experimental design}

Field experiment was conducted in Khumaltar, Kathmandu in autumn seasons of 2007 and 2008. Khumaltar is located in $85^{\circ} 20^{\prime} \mathrm{E}, 27^{\circ} 40^{\prime} \mathrm{N}$ at an altitude of $1368 \mathrm{~m}$ above sea level. Because of limited seeds and large number of entries, augmented design was used with five incomplete blocks. Three controls namely Kabre Tite, Dolpa Tite and Khumal Tite were randomized in each block, then the new entries (accessions of Tartary buckwheat) were placed in the remaining plots. The plot size was two rows, one $\mathrm{m}$ long rod row with a $25 \mathrm{~cm}$ row to row distance and 75 $\mathrm{cm}$ block to block. A rod row system (solid seeded or continuous row) of planting was followed. Equal amount of seeds (approximately $5 \mathrm{~g}$ ) for each entry was seeded and farmer's systems of cultural practices were followed, for example, rainfed system, mixing compost during land preparation, application of NPK just before seeding, dropping seeds in furrow, two time weeding (first after two weeks of seeding and second at flowering time), sun drying of seeds and straw, etc. NPK was applied at the rate of 30:30:0 kg/ha and compost at the rate of $5 \mathrm{t} / \mathrm{ha}$.

\section{Data collection}

Observations were made on an individual plant basis based on the Descriptors for buckwheat (IPGRI 1994). For measurement, three to five individual plants or plant's parts were considered and averaged data were used for analysis. Individual plants that were considered for data recording were tagged with color rope, so that data could be collected from the same plant in other crop stages. For separating branch and inflorescence, presence or absence of leaf was considered. The traits used in biplot analysis along with their abbreviation were plant height (PLHT), numbe of primary branches (PRMBRAN), number of leaves (LFNO), days to maturity (MATDAYS), 500grain weight (500-GRWT), number of grain per plant (GR/PL) and grain yield per plant (GRYLD/PL).

\section{Genotype by trait biplot analysis}

Statistical analysis was done separately for each year. Analysis of variance (ANOVA) for augmented design was done using SAS software based on Scott and Milliken (1993). In augmented design, the analysis estimates block effects and plot error using checks. Block effects then are used to adjust new entries and the error derived from controls then is used to obtain valid statistical tests of differences among entries (Scott \& Milliken 1993). There were significant differences for plant height, maturity days, grain number and grain yield in both years. Significant differences were not observed for primary branches and leaf number, and 500-grain weight in both years. Both significant and non-significant traits were taken for GT biplot analysis because of their importance roles on grain yield and adaptation.

Top six accessions (referred them as landraces) i.e., Ghyuri (NPGR-06508, collected from Solukhumbu district), MY-2-33-1 (NPGR-11297, collected from Dolakha district), Mukte (NPGR-00489, collected from Dhankuta district), Bijuwar (NPGR-02191, collected from Terhathum district), Talphi (NPGR-06682, collected 
from Okhaldhunga district) and Tan-1 (NPGR-02204, collected from Solukhumbu district) in term of grain yield per plant and one standard variety, i.e. Kabre Tite (check) were selected for biplot analysis from these 105 accessions of eastern collections. Kabre Tite (NPGR-11322) was considered as standard variety because this variety has been used in many buckwheat trials over years and locations. Kabre Tite is originally collected from $2652 \mathrm{~m}$ altitude of Solukhumbu district in eastern Nepal. These landraces were repeated over the years and averaged data was used.

A GT biplot was constructed by plotting the $\mathrm{PC}_{1}$ scores against the $\mathrm{PC}_{2}$ scores for each genotype and each trait using GGE biplot software (Yan 2001). To display the genotype by trait two-way data in a biplot, the following formula was used (Yan \& Rajcan 2002).

$$
\frac{T_{i j}-\bar{T}_{j}}{s_{j}}=\lambda_{1} \zeta_{i 1} \tau_{j 1}+\lambda_{2} \zeta_{i 2} \tau_{j 2}+\varepsilon_{i j}
$$

$\underline{w}$ where $T_{i j}$ is the average value of genotype $i$ for trait $j$, $\bar{T}_{j}$ is the average value of trait $j$ over all genotypes, $\mathrm{s}$ is the standard deviation of trait $\mathrm{j}$ among the genotype averages; $\lambda_{1}$ and $\lambda_{2}$ are the singular values for the first and second principal components; $\zeta_{11}$ and $\zeta_{12}$ are the $\mathrm{PC}_{1}$ and $\mathrm{PC}_{2}$ scores, respectively, for genotype $\mathrm{i} ; \tau_{j 1}$ and $\tau_{j 2}$ are the $\mathrm{PC}_{1}$ and $\mathrm{PC}_{2}$ scores, respectively, for trait $\mathrm{j}$; and $\mathrm{a}_{\mathrm{ij}}$ is the residual of the model associated with the genotype $\mathrm{i}$ in trait $\mathrm{j}$. This model standardizes the data and was used because, different traits had multiple units.

\section{Results and Discussion}

Considering the furthest genotypes from the biplot origin, a polygon was first drawn on genotypes so that all other genotypes are within the polygon (Figure 1). Then perpendicular lines to each side of the polygon were drawn, starting from the biplot origin. The perpendicular lines are equality lines between adjacent genotypes on the polygon, which facilitate visual comparison (Yan \& Tinker 2006). The equality lines divided the biplot into sectors, and the winning genotype for each sector is the one located on the respective vertex (Yan \& Tinker 2006). The distance between two genotypes approximates the Euclidean distance between them, which is a measure of the overall dissimilarity between them. The length of the genotype vector, which is the distance between a genotype and the biplot origin, measures the difference of the genotype from the average genotype. Therefore, genotypes located near the biplot origin have little contribution to both genotype and genotype

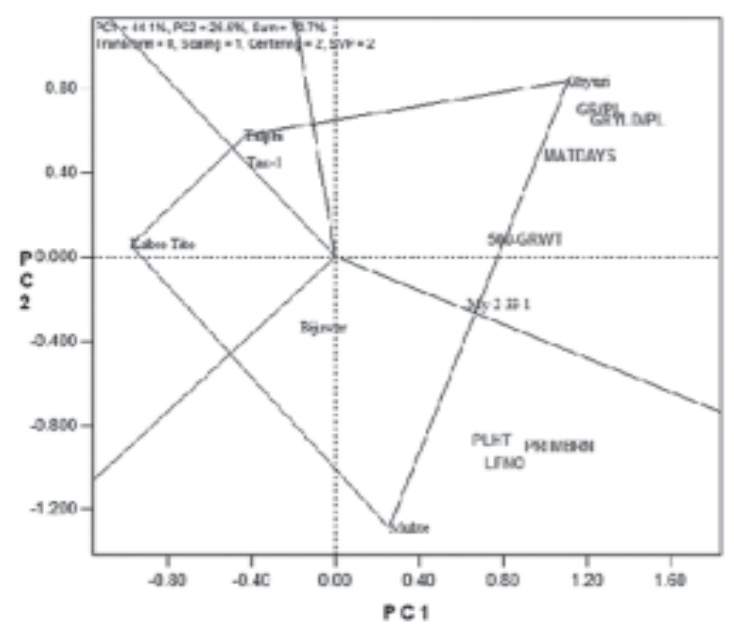

Fig. 1. Biplot of seven landraces of Tartary buckwheat collected from East Nepal, showing which entries was best for what traits

PLHT, Plant height. PRMBRAN, Number of primary branches. LFNO, Number of leaves. MATDAYS, Days to maturity. 500-GRWT, 500-grain weight. GR/PL, Number of grains per plant. GRYLD/PL, Grain yield per plant. PC, Principal component.

by trait interaction and genotypes with the longest vectors are either the best or the poorest for a particular group of traits.

The first two PCs accounted for $70.7 \%$ variation. The contributions of Ghyuri and Kabre Tite were higher in $\mathrm{PC}_{1}$ and of Mukte and Ghyuri in $\mathrm{PC}_{2}$ (data not shown). Considering traits, number of grains and grain yield were found to be more important in explaining variation in $\mathrm{PC}_{1}$ and number of primary branches and leaves in $\mathrm{PC}_{2}$. The landrace, Ghyuri had the highest values for grain yield (5.36 g per plant) and number of grains (276), but late in maturity (91 days) (Figure 1). Plant height, number of leaves and primary branches of Ghyuri were closed to Mukte in biplot, indicating Mukte had higher values for these three traits. The landraces with the lowest values for one or more traits are graphically shown in Figure 2. The weight of 500grain was the lowest (8.08 g) in Kabre Tite. Talphi and Tan-1 were the lowest in number of leaves, plant height and number of primary branches.

Two landraces, i.e., Ghyuri and Kabre Tite were compared and biplot result is given in Figure 3. A perpendicular line on the line which joined two landraces separates the entries and traits. All traits are on the same side of Ghyuri which indicates that Ghyuri followed by MY-2-33-1 had higher values for all these traits compared to other landraces. 


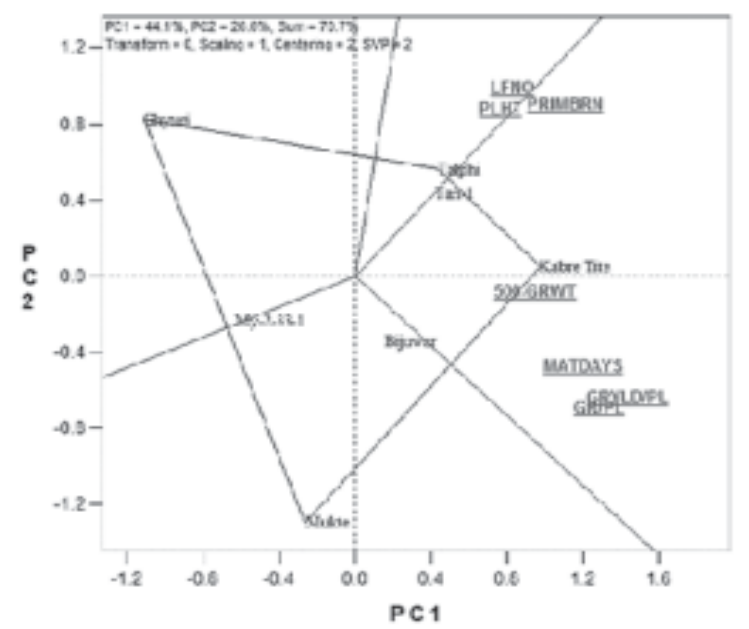

Fig. 2. Plot showing negative traits with respect to seven landraces of Tartary buckwheat collected from East Nepal

PLHT, Plant height. PRMBRAN, Number of primary branches. LFNO, Number of leaves. MATDAYS, Days to maturity. 500GRWT, 500-grain weight. GR/PL, Number of grains per plant. GRYLD/PL, Grain yield per plant. PC, Principal component.

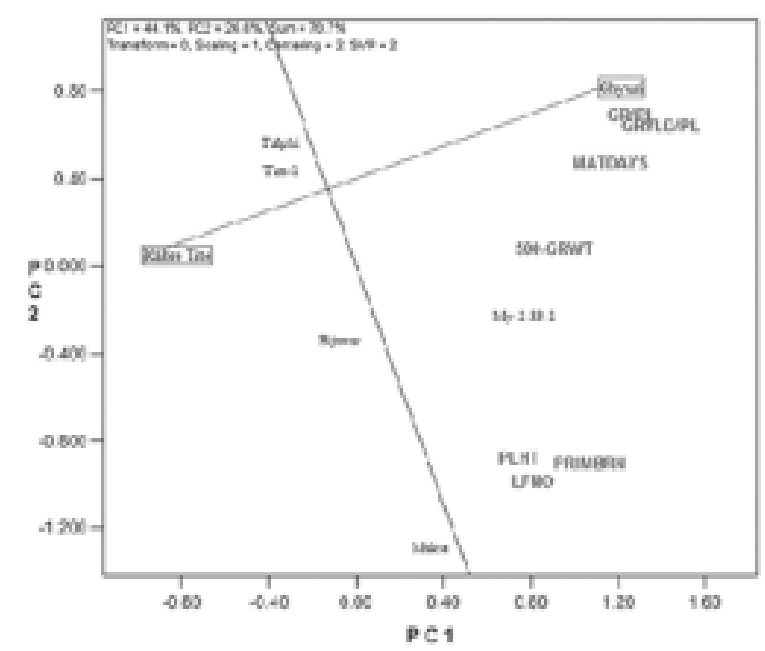

Fig. 3. Probability of difference in grain yield $(\mathrm{P}<0.006)$ between Kabre Tite and Ghyuri landrace

PLHT, Plant height. PRMBRAN, Number of primary branches. LFNO, Number of leaves. MATDAYS, Days to maturity. 500GRWT, 500-grain weight. GR/PL, Number of grains per plant. GRYLD/PL, Grain yield per plant. PC, Principal component.

Relationship among these seven traits is shown in Figure 4. If there is an acute angle made by lines originated from the origin to the traits, the correlation between them is positive and if angle is obtuse, relationship is negative (Yan 2001). Close associations were found among grain yield, number of grains and days to maturity. Similarly, plant height, number of

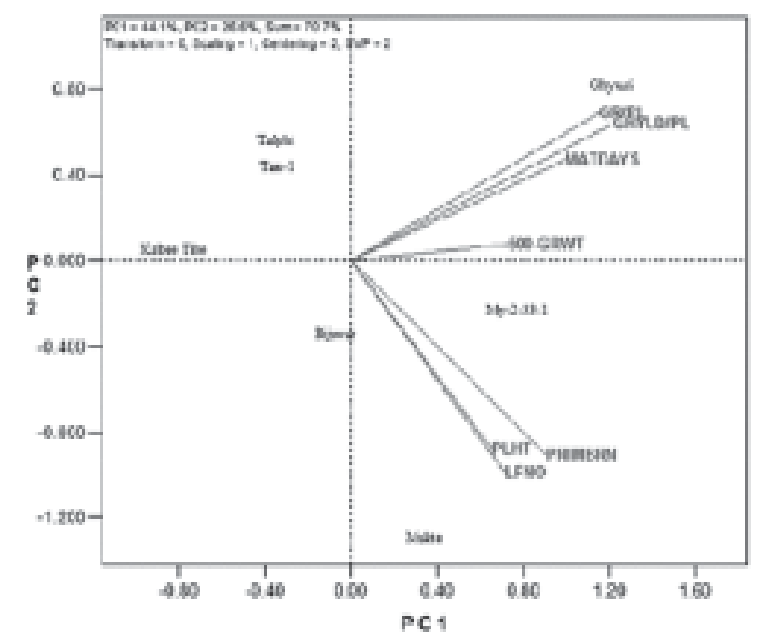

Fig. 4. Relationship among seven traits measured in seven landraces of Tartary buckwheat collected from East Nepal

PLHT, Plant height. PRMBRAN, Number of primary branches. LFNO, Number of leaves. MATDAYS, Days to maturity. 500-GRWT, 500-grain weight. GR/PL, Number of grains per plant. GRYLD/PL, Grain yield per plant. PC, Principal component.

leaves and number of primary branches were closely related with each other. Contrast negative association was not observed among these traits. These landraces were ranked based on grain yield which is depicted in Figure 5. Landraces below the

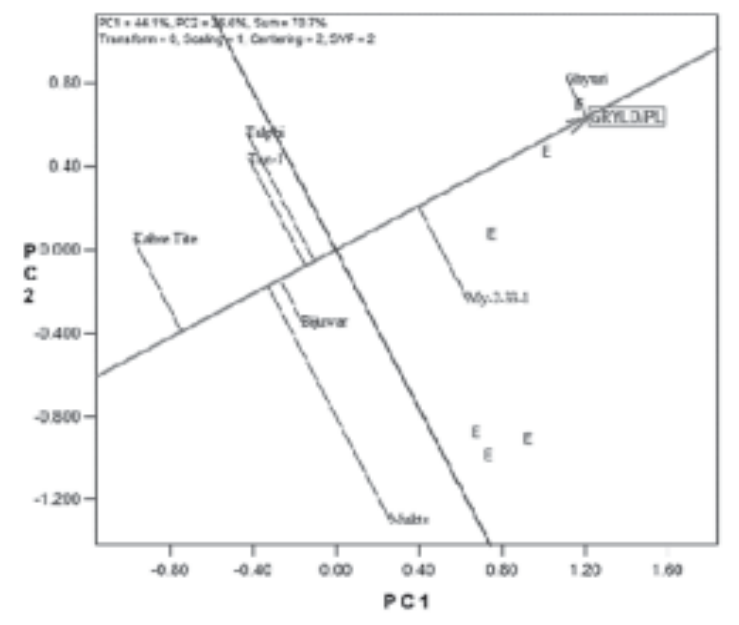

Fig. 5. Examining the performance of seven landraces of Tartary buckwheat collected from East Nepal in relation to grain yield per plant.

E, Represent different traits. GRYLD/PL, Grain yield per plant. PC, Principal component. 
perpendicular line yielded below the average. All landraces except Ghyuri and MY-2-33-1 were placed below perpendicular line. Based on the grain yield, Ghyuri was the best followed by MY-2-33-1 (3.45 g per plant). Considering two traits, Ghyuri also appeared distinctly at the top of the arrow line which shows the increasing point value (Figure 6).

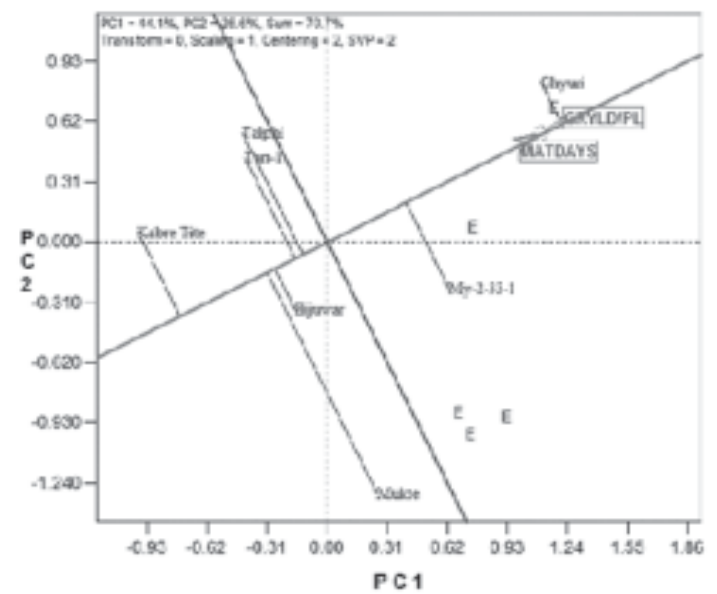

Fig. 6. Evaluation of landraces of Tartary buckwheat collected from East Nepal based on the two traits, i.e., days to maturity and grain yield

E, Represent different traits. MATDAYS, Days to maturity. GRYLD/PL, Grain yield per plant. PC, Principal component.

Kabre Tite was considered standard variety and it was compared with other landraces (Figure 7). The concentric rings allow to compare the landraces with

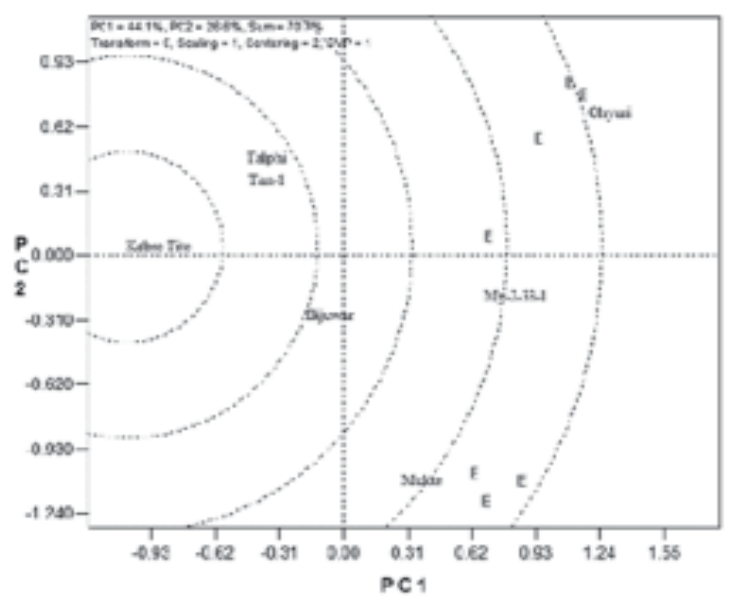

Fig. 7. Comparison of six landraces of Tartary buckwheat collected from East Nepal considering Kabre Tite as reference variety

E, Represent different traits. PC, Principal component.
Kabre Tite. Talphi and Tan- 1 were closer to the central concentric ring, indicating these landraces similar to Kabre Tite for these seven quantitative traits. Ghyuri followed by MY-2-33-1 and Mukte were appeared the farthest from the Kabre Tite that means they were different from the standard variety, i.e., Kabre Tite for these studied traits. What is good with standard variety was shown in Figure 8. Kabre Tite had below average values for all these traits i.e. plant height, grain yield, number of leaves, number of grains, days to maturity, 500-grain weight and number of primary branches.

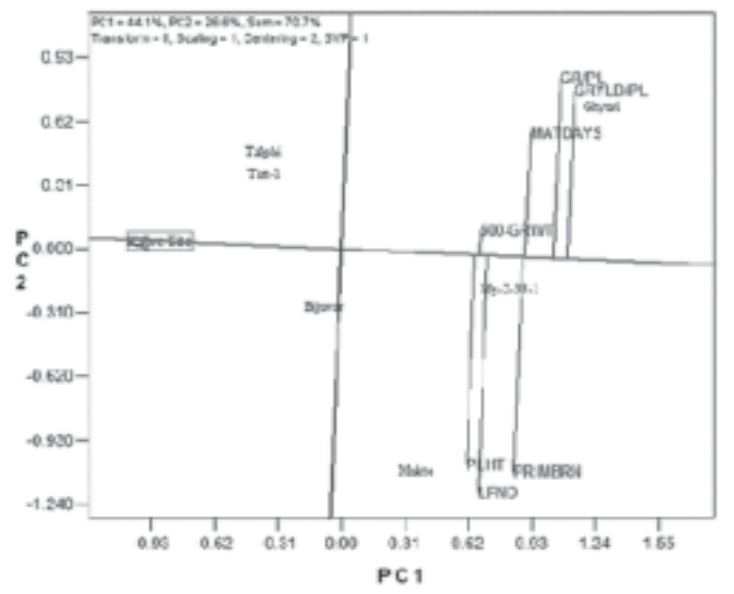

Fig. 8. Examining the performance of Kabre Tite

PLHT, Plant height. PRMBRAN, Number of primary branches. LFNO, Number of leaves. MATDAYS, Days to maturity. 500-GRWT, 500-grain weight. GR/PL, Number of grains per plant. GRYLD/PL, Grain yield per plant. PC, Principal component.

Graphically visualizing the merits and defects of genotypes, could enhance the breeding work more efficiently and effectively. Based on the traits profile of landrace, breeding objectives can easily be determined. For example, MY-2-33-2 had larger seed size (9.06 g) and Mukte had more number of leaves (11). This particular trait can be transferred to other promising landraces e.g., Ghyuri. Depending on the target environments and farming communities, importance of traits varied. Therefore, selection strategy might be either use of single trait or more than single traits during evaluation. Grain yield and days to maturity are the two most important traits. GGE biplot indicated that Ghyuri was ranked first either considering single grain yield trait or both grain yield and days to maturity. Biploting of genotypes along 
Nepal Journal of Science and Technology Vol. 13, No. 1 (2012) 1-6

with their trait values is also useful for identifying redundant traits and culling of landraces. All the landraces that have values below average can be discarded. If culling were conducted on only one trait, selection efficiency would be very limited. Independent culling based on multiple traits; however, can jointly achieve high selection intensity. Because of the single environment based data, only a genotype by trait biplot was used. Yan and Kang (2003) suggest that, if there are no clear cut genotype by environment pattern, a genotype by trait biplot based on values across all environments should be suffice. If there are clear cut clusters of environments, a genotype by trait biplot should be constructed and studied for each cluster of environments.

The landraces of Tartary buckwheat studied were significantly different for many characters, including yield and yield components. Variation was also noticed at intra-landraces which indicate that, pure line selection can be effective. Four landraces, Ghyuri, MY2-33-1, Kimlinge and Sukha from East Nepal were top grain yielders on an individual plant basis. Ghyuri were found to be the best landrace based on the GT biplot analysis.

\section{References}

Baniya, B.K., M.L. Baidya, D.R. Sharma, D.M.S. Dongol, I. Paudel and H.P. Bimb. 2001. Study of Nepalese Tite buckwheat landraces at diversed agro-ecological regions of Nepal. In: Proc. National Workshop Buckwheat, Kathmandu (Eds. H.P. Bimb \& B.K. Joshi). Nepal Agricultural Research Council, Kathmandu. Pp. 157-165.

Baniya, B.K., D.M.S. Dongol and N.R. Dhungel. 1995. Further characterization and evaluation of Nepalese buckwheat (Fagopyrum spp.) landraces. In: Current Advances in Buckwheat Research. Ina, Japan. Pp. 295304.

Bimb, H.P., S. Fukuoka, K. Ebana and T. Nagamine. 2001. Genetic diversity in Nepalese populations of Fagopyrum tataricum revealed by RAPD assays. In: Proc. National Workshop, Kathmandu (Eds. H.P. Bimb \& B.K. Joshi). Nepal Agricultural Research Council, Kathmandu. Pp. 108-116.

Campbell, C. 1995. Inter-specific hybridization in the genus
Fagopyrum. In: Proceedings of the 6th International Symposium on Buckwheat. Ina, Japan. Pp. 255-263.

Campbell, C.G. 2003. Buckwheat crop improvement. Fagopyrum 20:1-6.

Dehghani, H.E., A. Ebadi and A. Yousefi. 2006. Biplot analysis of genotype by environment interaction for barley yield in Iran. Agronomy Journal 98:388-393.

Fabjan, N., J. Rode, I.J. Košir, Z. Wang, Z. Zhang and I. Kreft. 2003. Tartary buckwheat (Fagopyrum tataricum Gaertn.) as a source of dietary rutin and quercitrin. Journal of Agricultural and Food Chemistry 51:64526455.

Honda, Y. 1992. Present status of buckwheat breeding in Hokkaido. Nogyo Gijutsu 47:342-346.

Inoue, N., H. Kumagai and M. Hagiwara. 2002. Improvement of fertilization rate by mass selection in common buckwheat. Fagopyrum 19:49-53.

IPGRI. 1994. Descriptors for buckwheat: Fagopyrum spp. Bioversity International, Rome, Italy.

Joshi, B.K. and K. Okuno. 2010. A genotype by trait biplot analysis for multiple traits-based selection of genotypes of Tartary buckwheat. Fagopyrum 27:1319.

Scott, R.A. and G.A. Milliken. 1993. A SAS program for analyzing augmented randomized complete-block designs. Crop Science 33:865-867.

Sherchand, K., and A. Ujihara. 1995. Studies on some morphological and agronomical traits of buckwheat in Nepal. In: Current Advances in Buckwheat Research. Ina, Japan. Pp. 285-293.

Yan, W. 2001. GGEbiplot: A windows application for graphical analysis of multi-environment trial data and other types of two-way data. Agron. J. 93:1111-1118.

Yan, W. and J.A. Frégeau-Reid. 2008. Breeding line selection based on multiple traits. Crop Science 48:417-423.

Yan, W. and M.S. Kang. 2003. GGE biplot analysis: A graphical tool for breeders, geneticists, and agronomists. CRC.

Yan, W. and I. Rajcan. 2002. Biplot analysis of test sites and trait relations of soybean in Ontario. Crop Science 42:11-20.

Yan, W. and N.A. Tinker. 2006. Biplot analysis of multienvironment trial data: Principles and applications. Canadian Journal of Plant Science 86:623-645.

Yan, W.H., L.A. Hung, Q. Sheng and Z. Szlavnics. 2000. Cultivar evaluation and mega-environment investigation based on the GGE biplot. Crop Science 40:597-605. 